\title{
PARENTS' DESCRIPTIONS OF BARRIERS FACED AND STRATEGIES USED TO OBTAIN DENTAL CARE*
}

\author{
By P. Jean Frazier, MPH, ${ }^{* *}$ Joanna Jenny, EdD, ${ }^{* *}$ and \\ Robert A. Bagramian, DDS, DrPH $\nmid$
}

\begin{abstract}
Regardless of the length of this paper, developed by reporting so many family vignettes, a large amount of personal information has been presented for understanding the reactions of parents who try to get their children treated.
\end{abstract}

Richards ${ }^{3}$ has compiled a comprehensive bibliographical review of studies which describe factors related to the utilization of dental services in the United States and other countries. Examples of variables described in the differential use of dental services include financing, anxiety and fear, past experiences, perceptions and personalities of both providers and recipients of dental services, awareness of need for treatment, and factors affecting availability, accessibility, and acceptability of dental services. Richards points out that utilization of dental services is a complex product of both present and past factors, and includes differences in the social, economic, and demographic characteristics of the population studied. Utilization in any society, hence, is dependent on a variety of factors, some of which may be rooted in previous practices, cultural values, and familial traditons.

The financial barrier is but one of the many types of barriers which may face families who seek dental care. Other barriers, perhaps less obvious than the financial one, but equally as great an impediment to utilization, may be psychological, environmental, cognitive, or sociological. For example, Nikias ${ }^{2}$ calls attention to the importance of social class as a factor which affects utilization even when cost as a barrier is removed. She states that social class maintains a strong correlation even when ability to pay for services no longer is a problem.

A model of utilization for dental treatment, presented by Young and Striffler, ${ }^{5}$ describes a common way of looking at utilization by a population. This model assumes that need for dental care is nearly universal. Three possible responses to this need for care then are defined in the model: (1) persons who demonstrate an unqualified desire for dental care plus the ability to obtain dental services are said to be responding with effective demand, inasmuch as they want the care and are able to obtain it; (2) persons who may have the desire for dental care but who are not able to obtain services are said to be responding with potential demand, because they want the care but for some reason do not obtain it; and (3) persons who may choose deliberately not to obtain care are considered to demonstrate no demand because they may not be aware of their need or they may not desire dental services.

Studies of utilization of dental care appear to have focused mainly upon families who represent the effective demand as defined by Young and Striffler. Less information is available about the families with potential demand and those who demonstrate no demand. It is not easy to identify the factors which influence the decisions to seek care by the last two categories because the families are unknown and hidden within the

\footnotetext{
* Supported by PHS Grant DH 00183-01

** Assistant Professor, Division of Health Ecology, School of Dentistry, University of Minnesota,

***Associate Professor, same address

tAssociate Professor and Chairman, Department of Community Dentistry, School of Dentistry,
University of Michigan, Ann Arbor 48104
} 
community. Often it may be assumed that care is not desired or that the family does not perceive or recognize the need because it does not care about dental health or does not value dental services.

While barriers other than the financial ones may manifest themselves in the same outcome-a family or child not receiving routine care or needed treatment-they seem to be recognized infrequently as real barriers. As a result, they are less well understood and less often studied in a systematic manner than are financial barriers. Little is known about the circumstances which may be keeping families from moving out of no demand or potential demand to the category of effective demand. Because the process of studying the circumstances of these families is complex and expensive, little is known today about their priorities and decisons.

In the study now to be reported, an approach was utilized which made it possible to gather information from a sample of families in which a school-age child was identified as needing dental treatment, and who, within one year, did or did not receive the needed treatment so that he could be classified in terms of the model on utilization. ${ }^{5}$ The purpose of this report is to present a qualitative portrayal of two groups of families through narrative-findings which describe (1) the barriers, perceived by some families, which kept them from obtaining needed treatment, and (2) the strategies, used by other families, who were successful in obtaining treatment. An intimate glimpse of both groups of families and their perceptions of the problems that they faced in obtaining dental treatment, within the available system of providing dental care, now will be presented.

\section{Procedure}

The procedure for gaining information was initiated in 1970 as a project in a large midwestern school district to study the effects of various dental-health behaviors on children's oral health. The sequence of steps carried out between May 1970 and November 1971 is summarized in Figure 1. Each step will be discussed in some detail.

Step 1. An examination of 984 Caucasian third-grade children by a dental epidemiologist was utilized to obtain a baseline for screening. A priority for treatment was assigned to each child which indicated his need for treatment. Each child was designated as needing dental treatment when an obvious carious lesion was identified in a permanent tooth or teeth. This criterion was used because a dentist most likely would elect to treat this condition to prevent the loss of teeth, whereas he might elect not to treat a lesion in a primary tooth. Of the original sample of 984 children, 192 were identified as needing treatment based on the criterion of the study.

Step 2. Parents were notified by mail that their third-grader was in need of treatment. The letter did not mention the specific tooth or teeth identified as needing treatment. Included with the letter was a list of resources available for dental care in the City, with telephone numbers and street addresses.

Step 3. Between the baseline dental examination and the second dental examination, parents of all children, identified as needing dental treatment, were interviewed by a trained interviewer who resided in the community to obtain demographic data and information on the family's dental attitudes and behaviors. Interviewers also talked with a sample of parents of children who were not identified as needing treatment. The interviewers were not aware of the child's status in regard to treatment needed.

Step 4. A follow-up dental examination was carried out for $159^{*}$ children in May 1971, a year after the original baseline examination and notification of the parents that their children needed care. The re-examination provided objective evidence when

\footnotetext{
* By this time, 33 of the children had moved out of the school district and had to be eliminated from the sample studied. Those children who moved to other elementary schools within the same district were followed to their new schools.
} 
FIGURE 1

FLOWCHART OF PROCEDURES

DENTAL HEALTH BEHAVIORS' PROJECT

$1970-71$

STEP 1

May 1970

Dental Screening Examination( $N=984$ )

to Identify Children in Need of Treatment

192 Children in Need of Treatment

(Obvious Carious Lesion on a Permanent Tooth or Teeth)

STEP 2

June 1970

Parents Notified by Mail

STEP 3

July 1970-

Apri1 1971

Parent-Interviews

STEP 4

May 1971

Dental Re-Examination of Children Needing Treatment, $(N=159)$

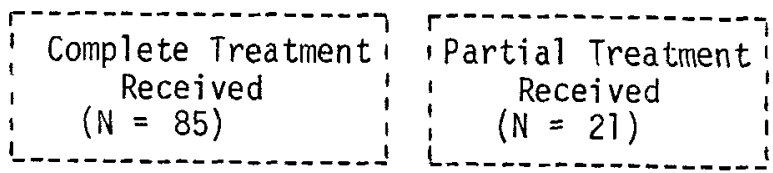

No Treatment Received $(N=53)$

Quantitative Analysis of Factors

Explaining Variability in Obtaining Dental Care

for Children - Based on Interview-Data From Step 3

STEP 6

June -

Nov. 1971

Data-Collection: Strategies and Barriers Perceived by Families of Children Needing Dental Treatment 
treatment had been received. Parents of children still needing treatment again were notified by mail.

At this point, the children were assigned to three categories:

1. Completed treatment $(N=85)$ for children by May 1971 of needs identified

by the project;

2. Partial treatment $(N=21)$ for children who had received some dental treatment, but for whom the identified needs were not completed; and

3. No treatment $(N=53)$ for children who showed no evidence of any dental treatment since the baseline dental examination one year earlier.

Step 5. Utilizing the data for the family from the interview in Step 3, an earlier paper $^{4}$ was used as a pattern for presenting a quantitative analysis of the factors which explained the variability in obtaining or not obtaining treatment. An analysis then was carried out in which the independent variables such as sociological, psychological, economic, environmental, and cognitive factors were regressed against the dependent variable of obtaining complete, partial, or no treatment within one year. It was found, while economic factors explained the greatest variance, that other factors associated with acceptability of the dentist ranked second in explaining the variance. Examples of factors included in this category were perceived inability to find a dentist "you like," who is "good with children," and who "does good work"

Step 6. Following the second examination for dental screening in May 1971, as many as possible of the 159 families were interviewed again by a trained resident of the community. These interviews were conducted by different individuals than those who had interviewed the families in Step 3. The purpose of this step was to obtain qualitative, descriptive data, which related to the strategies and barriers in obtaining dental treatment, from the parents of those children who had received complete, partial, or no dental treatment during the preceding year.

During the summer of 1971 , four interviewers were hired and trained to document the care-seeking experiences of the 159 families. Using a case-log approach, assignments were made to the interviewers to collect reactions from two types of families:

1. for those who had obtained completed or partial treatment for the child during the year, to document the strategies utilized by the family to obtain the care, and answer the question, "How did this family seek and obtain the care?";

2. for those families who had not obtained treatment for the child during the year, to document the barriers faced, from the family's point of view, and then assist the mother to obtain the needed care for the child.

Folders were maintained for each of the families in which to place the responses to the earlier interview, the child's status in dental treatment, and the case-log descriptions of families' strategies to obtain care or the barriers to obtaining care.

\section{Findings as Vignettes of Families' Strategies and Barriers}

Table 1 presents the number of children in each of four socioeconomic levels* for status in accord with receipt of completed treatment, partial treatment, or no treatment during the previous 12-month period. The SES status for each family was derived by combining specific information regarding the parent's education, family income, and occupation of the main wage earner. The greatest weight was assigned to parental

\footnotetext{
* Occupation, education of the head of the household, and family income were combined in a formula suggested by Green ${ }^{1}$ to establish levels of socioeconomic status (SES). The formula was SES $=<0.59$ $\mathrm{x}$ education $)+(0.27 \mathrm{x}$ income $)+(0.25 \mathrm{x}$ occupation $)$. The education, income, and occupational scores were determined from tables also developed by Green in 1970 . The resulting scores for the SES index then were categorized into four levels, $(<50,50-60,60-70$, and $71<)$. The two lowest categories were low enough to include families receiving public assistance. Some families in the high SES category had a family income of $\$ 18,000$ or more.
} 
education (.59), followed by family income (.27), and occupation of the main wage earner $(.25) .^{1}$

The narrative findings will be presented in two parts. Part I will present vignettes of families in which the child, identified as needing treatment, showed no evidence of having received any dental treatment within the 12 -month period of the study. Part II will present vignettes of families in which the child identified as needing treatment, did receive the needed treatment within the year.

In both Parts $I$ and II, the family vignettes are presented in accord with the status of treatment of the child and the socioeconomic status of the family. While several vignettes are presented for each of the SES categories on status of treatment, the vignettes cannot be and are not intended to illustrate the average family or to be representative of the category. The categories, instead, and the individual case-histories have been selected to illustrate contrast and variety. Each describes the context of a particular family's circumstances and its response to receipt of notification that a child had been identified as needing dental treatment. Included is information from the family-interview (Step 3 of the Procedures) and from the second interview (Step 6) in the form of comments written by the community worker in the case-log.

The vignettes will be presented in accord with seven states of treatment-SES categories (See categories A - G as labeled in Table 1).

Table 1

Treatment-Status and Socioeconomic Status of Children

Identified in Need of Dental Treatment*

One Year Earlier

( $N=159)$

\begin{tabular}{|c|c|c|c|}
\hline \multirow{2}{*}{$\begin{array}{c}\text { Socioeconomic } \\
\text { Levels }\end{array}$} & \multicolumn{3}{|c|}{ Treatment Status } \\
\hline & None & Partial & Completed \\
\hline $\begin{array}{c}<50 \\
\text { (towest) }\end{array}$ & $\begin{array}{c}6 \\
\text { (Category A) }\end{array}$ & 2 & $\begin{array}{c}5 \\
\text { (Category D) }\end{array}$ \\
\hline $50-60$ & $\begin{array}{c}30 \\
\text { (Category B) }\end{array}$ & 6 & $\begin{array}{c}42 \\
\text { (Category E) }\end{array}$ \\
\hline 60.70 & $\begin{array}{c}9 \\
\text { (Category C) }\end{array}$ & 3 & $\stackrel{22}{\text { (Category F) }}$ \\
\hline $\begin{array}{c}70< \\
\text { (highest) }\end{array}$ & 0 & 1 & $\begin{array}{c}6 \\
\text { (Category G) }\end{array}$ \\
\hline $\begin{array}{c}\text { Complete SES } \\
\text { not available }\end{array}$ & 8 & 9 & 10 \\
\hline TOTAL & 53 & 21 & 85 \\
\hline
\end{tabular}

* The study's criterion for needing dental treatment was an obvious carious lesion identified on one or more permanent teeth.

PART I - No Treatment Received

All of the families described in Part $I$ are those in which a child had been identified as in need of dental treatment, but who showed no evidence of any treatment by a dentist since the baseline dental examination 12 months earlier. Every effort was made to obtain information about barriers to treatment from these 53 families. Although some families had moved as many as four times within the period of study, the community interviewers were able to trace most of the families to their new addresses. Some families had no telephone or the telphone had been disconnected and, it was not unusual for the interviewers to make anywhere from 10 to 15 visits before a final completion of an interview.

The family vignettes which follow are organized according to three SES categories, 
beginning with the lowest $<50$. No cases are presented for the $70<$ category, because no cases in which the child did not receive the needed treatment occurred within this highest SES group.

\section{CATEGORY A: No Treatment Received-SES $<\mathbf{5 0}$ (lowest)}

Six of the 13 children of families in the lowest category for SES showed no evidence of any dental treatment during the one-year period, although treatment was needed and the parents notified. The following statement describes one of these families, a mother who took a part-time job in order to pay the family's medical bills, with the result that her family no longer was eligible (barrier) for the lost-cost dental clinic where the children had been going regularly for some years.

Case No. $1 \mathrm{~A}$. No treatment, lowest SES category $(<50)$

Mrs. D, mother of three, married, husband a railroad carman, she is a part-time teacher's aide. Her education, 7 th-9th grade, and his 10 th-12th grade. Family income is $\$ 6,000-\$ 8,399 /$ year.

"She is interested in getting some help, because she cannot afford dental care. She had been taking the children regularly to the United Fund's dental clinic, but now that she works three hours a day as a teacher's aide her income is too high to be eligible for treatment there.

"She said that she asked the school to help her get into Pilot City Health Center, but the letter that she received from the school said that Pilot City was full. She called the University but could not get into its dental clinic. Then she called a Dr. _ that someone had recommended as being inexpensive, but he said that he was not accepting new patients.

"She said it takes everything that they both earn to make ends meet, and there is nothing left over for medical or dental bills. But, she will keep trying to find a dentist whom she can afford."

\section{CATEGORY B: No Treatment Received-SES 50-60 (second lowest)}

Thirty of the 78 children of families in the second lowest SES category showed no evidence of any dental treatment during the period of study. Many of these families perceived more than one type of barrier to obtaining the needed dental care. Ten family vignettes now are presented to illustrate the types of barriers which have kept families from obtaining the dental treatment which their child needed: (1) a child's extreme fear, (2) not knowing where to go, (3) ineligibility for the low-cost community resources, (4) lack of acceptability of dentistry and dentists, (5) overwhelming family problems, (6) unemployment, and (7) need for assistance in locating a resource for dental care.

Case No. 1B. No treatment, second-lowest SES category (50-60)

Mrs. G, mother of four, married, husband a welder, she is a housewife. Her education, 10 th-12th grade, her husband's 7 th- 9 th grade. Family income is $\$ 6,000-\$ 8,399 /$ year.

"Mrs. G had requested a visit because she was home-bound by a broken foot. She said that they went to a private dentist, but the child had not been treated. She fights going to a physician or a dentist. Just to get her to the physician for shots takes four people to hold her down. The mother says she, herself, is afraid of the dentist, and she has a problem with her children being afraid to the point that they get sick. She says that she has been careful not to let the children know how she feels, but they have the same fear that she has. She states with this child, that is is so embarrassing she just 'forgets' to take her. She knows that the child needs treatment, but it wears everyone out fighting to get this child to the dentist or physician."

Case No. 2B. No treatment, second-lowest SES category (50-60)

Mrs. D, mother of six, married, husband a radiator machinist, she a housewife. Her education, 10th-12th grade; her husband's, 7th-9th grade. Family income is 
$\$ 6,000-\$ 8,399 /$ year.

"The third-grader is not eligible for medical assistance. The two oldest children from a previous marriage are on AFDC funds. The family has enormous bills due because of the past year's strike, and consequently has never been able to meet bills. She hesitates to make any more bills when she already owes the dentist $\$ 45$. Last year when her husband was on strike they got behind five house-payments and almost lost their home. She said that her father-in-law by her first marriage was a dentist. When she got married he made her upper denture. When she was divorced, seven years later, she got the lower denture. She says that she tries her best to be conscientious about dental care."

Case No. 3B. No treatment, second-lowest SES category (50-60)

Mrs. P, mother of three, married, husband a janitor, she a clerk. Her education 1-3 years of college; her husband's education, a high school graduate. Family income is $\$ 8,400-\$ 10,799$.

"Mrs. P said that when they moved to the city three years ago they had many problems. Both parents got jobs to keep the family going-one income was insufficient. She said that she knows the children (twin third-graders both were identified as needing treatment) should see a dentist, but they don't have a dentist here. The one they had in the town from which they came made her feel that she neglected her children. Every time he looked at their teeth he went 'tut, tut.' She said that she felt uncomfortable, and always had a guilty feeling about going to the dentist.

"She said that their older daughter was accepted at the University clinic. They wanted to get the twins into the same clinic, but the children's clinic was filled. She said that they would keep on trying. Their income is too high for the low-income clinics. She works, and finds it hard to make appointments."

Case No. 4B. No treatment, second lowest SES category (50-60)

Mrs. K, mother of five, married, husband a block layer, she repairs hearing aids. Both have a high school education. Family income is $\$ 10,800-\$ 13,199$.

"Mrs. K had moved, and was not anxious to talk. She said that she was not about to take this child to the dentist until his teeth ached. The child had never been to the dentist. It did not seem to matter that the children had cavities-she insisted that she would only take them if their teeth hurt."

Case No. 5B. No treatment, second-lowest SES category (50-60)

Mrs. R, divorced, mother of five, is a clerical supervisor and a high school graduate. Her former husband is unemployed. Income is $\$ 6,000-\$ 8,399 / \mathrm{yr}$.

"Her main problem is financial unless she gets on AFDC. Because of the expenses and high rent, she cannot go to the dentist unless one of the children has a toothache. Her husband quit working in 1969 so she had to go to work to support her children. She is applying for AFDC and she will know soon whether she will be able to get on it."

Case No. 6B. No treatment, second-lowest SES category (50-60)

Mrs. B, mother of five, married. Husband disabled, she a housewife. Her education, $10-12$ th grade, his, $1-3$ years vocational school. Family income is $\$ 3,600-\$ 5,999 /$ year. AFDC.

"She wanted to talk about her personal problems, without much interest in the interview. Mr. B _ is an amputee and has been for years. They lost two sons-one died from pneumonia, and the other, from foul play. One of the other children found him hanging in the basement with his hands tied behind his back; he had been sexually molested. It was a terrible shock to the whole family.

"The father is unable to work for at least another year, if ever. No money is available for school-clothes; they are cut off from food stamps; somehow, they say she gets too much. Now she has to try to get food-shelf goods, and used clothes for the children.

"She said they have to pay for the two cemetery lots, the loan companies are on their neck, and managing things seems impossible. Their car broke down, was repaired, and 
now the agency is after her. They always have had to skimp, she said. She lives in the second house from the corner, so that she is ineligible for help by Model Cities. They just got on AFDC two months ago, so she said maybe things will be better." (This woman was referred to the AFDC worker.)

Case No. 7B. No treatment, second-lowest SES category (50-60)

Mrs. O, mother of eight; separated, she is a housewife. Her education, 12th grade, her husband's, 10th grade. Family income is $\$ 3,600-\$ 5,999 /$ year. AFDC.

'This child hasn't gone to the dentist for about a year and a half. Her husband would not let her run up any bills so all of the dental treatment has been let go. She is separated now, and on AFDC, so things are looking better for her.

"Her husband always said to hell with doctors and dentists. Now that they are separated, she has a dental appointment for this child on September 21st. She said that she had beautiful teeth when she got married, but she has lost them now because her husband would not let her go and have them repaired. She says that she is going to make sure that her children go at least once a year after their September appointments."

Case No. $8 B$. No treatment, second-lowest SES category (50-60)

Mrs. D, mother of one, married. Husband an insurance investigator, she a factory worker. Her education, 10th-12th grade, her husband a high-school graduate. Family income is $\$ 8,400-\$ 10,799$.

"They had moved, she has remarried, and says that this child has not been to the dentist for about three years-a matter of money. Mrs. D is sure that the child needs braces, and, because of this need has put off seeing a dentist. She said that they now have moved out of the area where low-cost clinics were available to them. We discussed the University's clinic, and she said she would try there, since the child has a second tooth which has erupted on top of another one.

"The mother said she doesn't care to go to the dentist; she has false teeth. She said that one dentist refused to work on her child, because when the dentist stepped in to the office, the child screamed and the dentist refused to treat her. The child says she is afraid of all "those instruments'."

Case No. 9B. No treatment, second-lowest SES category (50-60)

Mrs. E., mother of four, married. Husband is unemployed, she sells Tupperware. She is a high school graduate, he completed 7 th-9th grade. Family income is $\$ 3,600-\$ 5,999 /$ year. "She said that she and her husband both put off going to the dentist because they could not afford it. She hardly can make ends meet, because he is unemployed. Mrs. E has let her teeth go so long that she is afraid to go to the dentist now.

"The school referred her to the (United Fund) Clinic, and she called them the first part of May. She could not get an appointment until September, though, and she was disgusted that she had to wait so long.

"She said their mounting medical bills have been a strain-they still owe $\$ 700$ to General Hospital. She has applied for one of the Housing Authority's low rent houses, but has to wait until one is available. She feels bad that she lives in such a dilapidated apartment."

Case No. 10B. No treatment, second-lowest SES category (50-60)

Mrs. B, mother of two, married. Husband a letter carrier, she a secretary. She completed 10th-12th grade, her husband is a high school graduate. Family income is $\$ 10,800-\$ 13,199 /$ year.

"There was no particular problem-the mother just needed someone to help make arrangements. When asked if this child had been to the dentist, Mrs. B said 'no.' We went over the possible resources where she might call.

"I explained that I would be checking back with her another day. I learned that she had called the (United Fund) Clinic, found that she was eligible, and had an appointment." 


\section{CATEGORY C: No Treatment Received-SES 60-70 (second highest)}

Of the 34 families in the 60-70 SES category with children identified as needing dental treatment, nine did not obtain treatment for a child during the 12 -month period. High cost, fear, and distrust of dentist characterized the two family vignettes selected for presentation.

Case No. 1C. No treatment, second-highest SES category (60-70)

Mrs. F, mother of three, married to an insurance manager, she is a housewife. Her education, a high school graduate, her husband, 1-3 years of college. Family income is $\$ 15,600-\$ 17,999$.

"She said that the family never would qualify to get financial help for dental care since they have a good income, but she still cannot see paying such high prices for dental care that they do not feel is of good quality. She thinks that private dentists should be checked and enough pressure applied so they will be forced to perform good treatment. "The mother mentioned three different relatives who have had trouble with poor dental treatment. One dentist kept filling the bad teeth of her sister and her sister kept getting toothaches and was physically sick. Finally her physician ordered her to have all her teeth pulled. When they were pulled, she found out that they all were rotted inside. Their oldest daughter had a severe toothache and went to the dentist. The dentist said he could not extract it, but would fill the root canal for $\$ 200.00$. He drilled the tooth out completely and left it unfilled for the time-being. When she went back, he said her wisdom tooth had to come out. She wanted the bad tooth pulled and he said 'no.' She now is trying to get into the University's clinic. The family would be willing to go to the University where they would have confidence in the treatment. She does not trust dentists, and thinks that the cost is outrageous."

Case No. 2C. No treatment, second highest SES category (60-70)

Mrs. G, mother of two, married, husband a surveyor, she a bookkeeper. Both have 1-3 years of college education. Family income is $\$ 18,000 /$ year.

"They took this child to the dentist a few years ago and the dentist scared him so badly that he now does not want anything to do with dentists.

"The mother said that they could afford to go, but the family just does not like to go to a dentist. She says, since she works, by the time she has a day off, she had a million other things to do besides fighting with this child about going to the dentist.

"She thinks that dentists charge too much for the time and effort they spend and she has not found a dentist who, she felt, performed good dentistry."

(No cases are presented at this point for the $70<$ category because no cases were found within this group in which the child did not receive the needed treatment)

\section{PART II - Treatment Received}

All of the families described in Part II are those in which a child identified as needing dental treatment did, in fact, receive the needed treatment within one year. In many instances, when the family had obtained the needed treatment, the mother described not only the steps she had taken to obtain care (strategies), but also the barriers which had been overcome. One example is a family in which the mother "went to work" (strategy) in order to have enough money to overcome a financial barrier. The following vignettes now are presented according to four socioeconomic categories, beginning with the lowest $(<50)$.

\section{CATEGORY D: Treatment Received - SES $<\mathbf{5 0}$ (lowest)}

Five of the 13 children of families in this lowest SES category received treatment. Vignettes follow for four of these families. Two of the families utilized two different low-cost community dental resources, and another, a "dentist who would wait for his money," as their main strategies to obtain care. AFDC enabled another family to obtain treatment. 
Case No. 1D. Treatment received, lowest SES category $(<50)$

Mrs. L., mother of four, married, husband a janitor, she a housewife. Her education, 10 th-12th grade; her husband's, 7 th-9th grade. Family income is $\$ 3,600-\$ 5,999 /$ year.

"After Mrs. L received the letter from the University, she called the child's school and told them that she could not afford to go to the dentist. The school nurse referred her to a (United Fund) clinic.

"She called the Clinic and the nurse mailed her a form to fill out. She filled it out, mailed it back. She was eligible, but the nurse called her and said they were so booked with appointments that she could not get an appointment until school started. She took all of her children and was pleased with the treatment. The treatment was completed and the child received a card so that he could get a gold star at school. He is due to go back again, he had a large amount of treatment to be completed.

"She said she herself could not afford to go and all of their teeth needed care. She was real glad to have the children's teeth treated at least, and is real pleased with the clinic." Case No. 2D. Treatment received, lowest SES category $(<50)$

Mrs. R, mother of four, married, husband self-employed in seasonal roofing, she a housewife. Her education 7th-9th grade, her husband's, 10th-12th grade. Family income is $\$ 3,600-\$ 5,999 /$ year.

"She said that they went to Pilot City before the project began, so that when the child needed work she waited until his six-month checkup and went to the clinic. She likes Pilot City because they send reminder cards a couple of days in advance of the appointment's date. She uses Pilot City Health Center for all of the children and they like it.

"The only problem she said was the long wait to get their first appointment ... it took almost a year. She said it was really frustrating, but she wouldn't change now. Welfare pays for the child's dental care."

Case No. 3D. Treatment received, lowest SES category $(<50)$

Mrs. C, mother of three, married, husband a truck driver, she a housewife. Her education 10 th-12th grade, he a high school graduate. Family income is $\$ 3,600-\$ 5,999 /$ year. AFDC. "Mrs. C has had problems. The child was in the hospital from the time she was 10 weeks of age until she was three years old and she had one kidney removed. The mother had a breakdown over this surgery, and her husband got into some trouble and is in prison. The child has had to take a large amount of medicine, and Mrs. $\mathrm{C}$ thinks that the medicine makes her teeth soft. She said that they had been seeing a dentist who filled the children's teeth, but the fillings dropped out. He was so rough with the children that they did not want to go back so, after listening to the kids, she decided to change dentists. She made an appointment with a different dentist and both she and the children like him. He explains as he goes along, so the children know what he is doing. "AFDC is helping her until her husband gets out of prison. But when he gets out he is to pay part of what he has saved back to AFDC. She, therefore, still will have problems with finances."

Case No. 4D. Treatment received, lowest SES category $(<50)$

Mrs. C, mother of seven, married, husband a truck driver, she a housewife. Her education, 10th-12th grade; husband's education, 10th-12th grade. Family income is $\$ 3,600-\$ 5,999 /$ year.

"She feels that dentists are much too high-priced and that they pressure people too much when they are already in a financial bind. She said both her dentist and physician did so until it made her so nervous that she does not make appointments when she feels she should.

"Mrs. C telephoned around to find a dentist who would wait for his money. He was the only one whom they found who would take their bad credit rating. She said the bill is so high for one child that none of the other children get to go. The mother also has an upper denture and needs her lower teeth pulled, but cannot afford the cost. She has hesitated 
about further dental treatment until she gets some of their present medical bills paid. Her husband took a cut in pay so that he could work here locally and be with the family, rather than away on an over-the-road job."

\section{CATEGORY E: Treatment Received - SES 50-60 (second lowest)}

Of the 78 families in the 50-60 SES category and with children identified as needing treatment, 42 obtained treatment during the study-period. Many of these parents indicated that they tried to maintain a regular pattern of making dental visits for the children, but not necessarily for the adults in the family. Others mentioned AFDC or welfare as the enabling factor which allowed them to obtain treatment for the children. Persistence characterized many of the mothers, and almost all mentioned family financial problems and the high cost of dental care. Many said they feel that it is important to obtain dental care for their children, but cannot afford regular care for themselves.

Eleven vignettes of these families now will be presented to illustrate the strategies used to obtain dental care-time payments, credit and bank plans, mothers taking new jobs, use of low-cost, community clinical resources, rationing dental care among the members of the family, and spending savings' accounts.

Case No. 1E. Treatment received, second-lowest SES category (50-60)

Mrs. A, mother of three, married, husband a painter, she a credit-manager at a store; her education, 1-3 years vocational school; his, a high school graduate, family income is $\$ 8,400-\$ 10-799 /$ year.

"Dentist's office called the mother to remind her to bring in child for six-month check-up. Mother made an appointment, took the child to office, treatment completed. The mother felt the cost of dentistry was high, but not high enough to keep from going. Their dentist has a 'bank-plan' charge-account and never complains when the family is late making payments. They try to pay all at once, but on occasion had to resort to credit."

Case No. 2E. Treatment received, second-lowest SES category (50-60)

Mrs. L, mother of seven, married, husband a maintenance-man for a moving company, she a housewife; both have 10th-12th grade educations. Family income is $\$ 6,000$ $\$ 8,399 /$ year.

"Mother made the usual yearly appointment and took the child to the office. The family dentist referred the child to the University of Minnesota Dental Clinic for braces (his bill would be close to $\$ 1,000)$. She was turned down. The University said it wasn't a condition needed for teaching students.

"They tried getting her admitted twice. The parents are heartsick about her crooked teeth. The mother seemed disgusted with dentists and the cost of dentistry.

"Even so, the family tries to get the kids in once a year. The last few years they have been able to do so because the kids do not have as many cavities as they did earlier. If there is too much treatment to be done, they have to let it pass, because they cannot afford it." Case No. 3E. Treatment received, second-lowest SES category (50-60)

Mrs. L, mother of three, married, husband a security-guard, she is a saleslady in a bakery, both have certificates from vocational school. Family income is $\$ 8,400-\$ 10,799$.

"She went to work so that she could get the child treated. She called a private dentist and made an appointment."

Case No. 4E. Treatment received, second-lowest SES category (50-60)

Mrs. P, mother of two, married. Husband is in prison, she works at two jobs, as a secretary and as a waitress. She had 1-3 years of Vocational School, and her husband's education is 10 th -12 th grade. Family income is $\$ 6,000-\$ 8,399$.

"Mrs. P said she had a dentist of her own, but had a bad experience with him-an injection of anesthetic which lasted three days. Her child had a tooth filled and then it fell out in six months. Mother started going to Pilot City when her husband went to 
prison because she thought that she could not afford a private dentist.

"When the child's report came about needing to go to the dentist, mother wanted her to go to Pilot City. She called Pilot City first, but could not get an appointment. She then tried the University, but could not get in. She also tried a couple of other agencies and could not get treatment. She was upset, when she received the letter, because she was determined to get some help.

"She called the Department of Public Health. They gave her a list of dentists to call. She told the Department about her problem with Pilot City. They (Public Health) made a call. She also kept 'bugging' them until her daughter finally was accepted. The child had 11 or 12 cavities. She likes Pilot City. Sees dentists there and has six-month check-ups. She thinks that the dentists are good, and the children like them."

Case No. 5E. Treatment received, second-lowest SES category (50-60)

Mrs. S, mother of two, husband a warehouseman, she works in a licensed day-care program. Both completed 10th-12th grade. Family income is $\$ 8,400-\$ 10,799$.

"She is afraid of the dentist herself, but she is interested and concerned about her children's dental health. She said that finances always have been a problem, but the dentist she has now lets her pay by the week or by the month, whichever is easier for the family, so she has had all of the children treated, and she feels it is easier to pay the bills when she takes them every six months."

Case No. 6E. Treatment received, second-lowest SES category (50-60)

Mrs. L, mother of five, husband a credit manager, she a housewife. Her education, 10th-12th grade, husband's education, 1-3 years of college. Family income is $\$ 13,200-\$ 15,599$.

"She made an appointment for this child just to see how much treatment was needed. She had some of the teeth completed. He needs to go again, but they cannot afford more until they get $\$ 500$ in other family dental bills paid."

Case No. 7E. Treatment received, second-lowest SES category (50-60)

Mrs. B, mother of five, husband a welder, she a housewife and waitress. Her educationhigh school graduate, husband's education 1-3 years of college. Family income is $\$ 10,800-\$ 14,199$.

"She had been going to a dentist who quoted her a price of $\$ 300$ for treating the children's teeth and they could not possibly afford it. She then called the Public Health Department and was referred to the (United Fund) clinic. She went there, liked the dentist, and it only cost her $\$ 70$ for all of the children. They gave her appointments for one year, and the children get the same dentist each time. Because she has to take the bus, transportation is a problem. She has had large dental expenses herself."

Case No. 8E. Treatment received, second-lowest SES category (50-60)

Mrs. F, mother of four, married, husband a machine operator, she a housewife. Both are high school graduates. Family income is $\$ 10,800-\$ 13,199$.

"Mrs. F has diabetes. Her oldest boy was 15 before he ever saw a dentist and had to have several fillings. They have had large hospital expenses, and it has been over 10 years since her husband has been able to afford to go to the dentist.

"When she received the letter she looked at the 'resources-sheet' and found that the (United Fund) clinic was close. She called ... they were eligible. The receptionist said to bring all of her children. Mrs. F said she had explained that they could not pay for it all at one time.

"On the first visit to the clinic all four children went, all had over seven cavities. It cost her over $\$ 40$ for the first visit. She was not anxious to go for the second appointment. But the receptionist called-Mrs. F explained that they could not afford the cost of finishing the treatment. The receptionist said that would be no problem; they would not have to pay it all at once.

"But when they got to the clinic and were through with the second round of 
appointments, the lady said to Mrs. F, 'Well, aren't you going to pay any of this?' It took Mrs. $F$ by surprise, she paid another $\$ 30$, left the Clinic, and will not go back."

Case No. 9E. Treatment received, second-lowest SES category (50-60)

Mrs. B, mother of four, separated, husband owns and operates an ambulance, she a housewife. Her education, 1-3 years of vocational school, he had 1-3 years of college. Family income is $\$ 3,600-\$ 5,999$, AFDC.

"Mrs. B said her husband had taken the child to one dentist, then they had a marital problem and the husband left home. She had to apply for welfare. In the meantime she had to file for bankruptcy and they were threatened with the loss of their home.

"Then one day one of the child's caps came off and she had to find a dentist close by within walking distance. She tried several because the dentists would not take welfare clients. They said they had to wait too long to get paid and it required too much paper work. She found a good dentist a few blocks away and had no problem getting an appointment. The child went twice and the rest of family too. She found him good with children.

"Problems she mentioned were financial, dentists who did not want to accept clients on welfare, and transportation (she has no car)."

Case No. 10E. Treatment received, second-lowest SES category (50-60)

Mrs. Q, mother of five, separated, husband repairs machines, she operates an address-ograph machine, both are high school graduates. Family income is $\$ 8,400-\$ 10,799 /$ year.

"She had made an appointment for the child, but in the interim her 16-year-old son had a dental emergency. She called this dentist, but could not get the son an appointment. Then she called another dentist from the telephone directory, and has been very grateful because he is so inexpensive in comparison. She said her husband was laid off from January until May, and with five children their dental bills amount to about $\$ 300 / \$ 400 /$ year. They take this amount out of their savings account. Now she is faced with having to get braces for one of the children."

Case No. 11E. Treatment received, second-lowest SES category (50-60)

Mrs. D, mother of one, married, husband a post-office clerk, she does telephone surveys. She a high school graduate, her husband's education, 10th-12th grade. Family income is $\$ 8,400-\$ 10,799 /$ year.

"Have regular appointments. Mrs. D is very strict about the dentist. She never went herself as a child and as a result had both dentures at 30 years of age. She said her folks could not afford dentists."

\section{CATEGORY F: Treatment Received -- SES 60-70 (second highest)}

Twenty-two of the 34 children of families in the 60-70 SES category received treatment within the 12 -month study period. Most of the parents in this category indicated some consistency in making regular appointments, but not necessarily for themselves. Usually the children have appointments to see the dentist on a routine basis, but still many of the families found the cost of dentistry too high.

Eight vignettes of these families will be presented, to illustrate their strategies for obtaining dental treatment for children identified as needing care-regular reminders from the dental office, making regular appointments in advance, and a dentist near the home. Case No. 1F. Treatment received, second highest SES category (60-70)

Mrs. B, mother of six, married; husband makes aluminum doors and windows; mother a nurse. She is a college graduate, father has had 1-3 years of college. Family income is $\$ 8,400-\$ 10,799 /$ year.

"The dentist's office calls two days in advance to remind them of appointments. They are having financial problems because the father is having open-heart surgery next week. She said ordinarily finances would not be a problem, but that Mr. B will not be able to work for a year at least after his surgery." 
Case No. 2F. Treatment received, second-highest SES category (60-70)

Mrs. L, mother of eight, married, husband a detective, she a housewife. Both have 1-3 years of college. Family income is $\$ 13,200-\$ 15,599 /$ year.

"Was upset to hear that her child needed to go to the dentist. She took him to their private dentist, and now thinks his treatment is completed."

Case No. 3F. Treatment received, second-highest SES category (60-70)

Mr. H, father of three, married, he a railroad engineer, she a housewife. Mother's education-high school graduate, his, 1-3 years of college. Family income is $\$ 10,800-\$ 13,199 /$ year.

"The mother takes the children to the dentist every six months. She usually makes the appointments in advance. The mother was not home when the interviewer made the visit. He said his wife had been in the hospital for over a month and was not expected home for quite a while yet. She was very ill and he seemed upset."

Case No. 4F. Treatment received, second-highest SES category $(60-70)$

Mrs. L, mother of three, married, her husband a production supervisor, she a housewife. Both are high school graduates. Family income is $\$ 8,400-\$ 10,799 /$ year.

"She tries to take the children regularly for dental visits. She said that she herself never went to the dentist regularly until six years ago when a brother-in-law (out-of-state dentist) was in dental school and convinced her to go. She said she would find every excuse possible to keep from going because she is afraid."

Case No. 5F. Treatment received, second-highest SES category (60-70)

Mrs. M. mother of four, married, her husband a mechanical designer, she a secretary; her education a high school graduate, her husband had 1-3 years of college. Family income is $\$ 8,400-\$ 10,799$.

"She said the children have been lucky so far, they have not had much trouble with teeth. They have a family dentist, and all of the children go-she had only one tooth to be filled."

Case No. 6F. Treatment received, second-highest SES category (60-70)

Mrs. W, mother of three, divorced, her former husband a parts man, she is a legal stenographer, both high school graduates. Her income is $\$ 10,800-\$ 13,199$.

"She does not take the kids to the dentist as often as she should because she is divorced and supporting herself and the kids and does not have the money. It cost her $\$ 300$ for the last year just on dental treatment for the kids.

"Their regular dentist was located downtown where it was too hard for her to get so she changed to a dentist who is located nearby, one block from home. The treatment is completed, but they have no future plans to go back."

Case No. 7F. Treatment received, second-highest SES category (60-70)

Mrs. W, mother of three, married, husband teaches at a junior college, she is a secretary. She has $1-3$ years of college, her husband has more than 4 years of college. Family income is $\$ 10,800-\$ 13,199$.

"She takes her children to a private dentist. She made an appointment for about a week later and treatment began. The children see the hygienist first who exposes the radiograph and checks their mouths. The children have more treatment to be completed."

Case No. 8F. Treatment received, second-highest SES category (60-70)

Mrs. C, mother of two, married, husband a general contractor, she a bookkeeper. Both are high school graduates. Family income is $\$ 18,000$ or more/year.

"She makes appointments six months in advance. She said she saw no reason why anyone would be unable to get to the dentist. They have a private dentist near their home. Mrs. C says they pay cash for the regular dental appointments, but for the orthodontist for the older girl they pay on a monthly basis." 


\section{CATEGORY G: Treatment Received - SES $70<$ (highest)}

All of the children of families in Category $G$, the highest SES category, did receive treatment during the one-year period. They all indicated that they seek dental care on a routine basis, although one mother stated that the family had taken out five loans to pay for the family's dental treatment. Three vignettes of these families now will be presented. Case No. 1G. Treatment received, highest SES category $(70<)$

Mrs. G, mother of three, married, husband works at an insurance company, she is a nursery school teacher. Both completed college. Family income is $\$ 10,800-\$ 13,199$.

"The family takes the kids to the dentist every fall at the start of school. They have had the same dentist for many years, and would not think of changing. The mother called the dentist a little sooner than usual because this child was having toothaches. Usually they cannot afford to go any sooner than necessary. They have taken out five loans for dental treatment for the family. She says it is difficult to keep abreast of other rising costs, let alone the high cost of dentistry."

Case No. 2G. Treatment received, highest SES category $(70<)$

Mrs. P, mother of three, married, husband a physician, she a housewife. She completed 1-3 years of college, he more than 4 years. Family income is $\$ 18,000$ or more/year.

"They have had the same dentist ever since Mrs. P was a small child. The nurse calls whenever the six-month check-up is due. She has a problem with her teeth, so she is extremely conscious of dental care for the children."

Case No. 3G. Treatment received, highest SES category $(70<)$

Mrs. Mc, mother of three, husband a pilot for a major airline, she is a hospital social worker; both have college bachelor's degrees. Family income is $\$ 18,000$ or more/year.

"Mrs. Mc said they all go regularly to the dentist and think it is an important thing to do. She calls the dentist every six months, and he makes the appointments. This child has been going since three years of age. She will need orthodontic treatment."

\section{Some Discussion}

This report presents family vignettes which illustrate qualitatively those families' circumstances, in addition to the lack of financial resources, which can contribute to a child's receipt or neglect of needed dental treatment. Prepared from the reports of community interviewers who interviewed each of the families, the vignettes present an informative glimpse of the lives and feelings of these families.

One group of families consisted of those who did not, or who were unable to obtain the needed dental treatment for a child. In the model for utilization of dental care presented by Young and Striffler ${ }^{5}$ these families would be clasified in the categories of potential-demand or no-demand. Almost none of these families was apathetic because the parent indicated a desire to obtain care for the children. Parents perceived a wide range of impervious barriers to their ability in obtaining the needed treatment. Lack of financial resources presented the most common barrier, but family situations, for example, large numbers of children, divorces and separations, double working-shifts, single-parent families, physically or mentally handicapped parents, prison-sentences, hospitalization and other major medical expenses, overwhelming family problems, and extreme fear on the part of the child or parent all contributed to the failure of children to receive dental treatment.

Lack of acceptability of dental treatment or the dentist was apparent when mothers described their own experiences and beliefs, or the past dental experiences of relatives, or the experiences of their own children. Many of these parents shared with the interviewers their reasons for distrust and dissatisfaction with dentistry. For some families an unawareness of the importance of dental treatment and a lack of understanding of the consequences of dental disease also contributed to the failure of a child to receive the dental care needed. In some families a particular child's turn to make the dental visit had 
to wait because other children in the family came first, either in order, or in terms of need for treatment. These families were rationing dental visits for their members.

Following the second dental examination and a second parental notification that a child still needed treatment, some of the families had made appointments by the time the second interview was conducted. In several instances these families had made numerous contacts to find a resource for dental care. In a few instances the parents indicated that treatment was underway for the child, but without explanation of the year-long lag in obtaining the needed treatment.

Originally, the intent was for the project's community workers to assist in any way possible those families who had been unable to obtain treatment for a child. In many instances, however, neither the community worker nor the staff of the project could help the family surmount such barriers as over-crowded community resources, financial ineligibility for the less-expensive dental services in the community, or community clinics which did not remain open during the summer months. The community worker could not assist when help was refused by one family that deliberately chose not to obtain treatment for the child until he had a toothache. The community workers, however, were influential in obtaining treatment for some of the children in need of treatment, and in a few instances, for entire families.

Another group of families, that did obtain the treatment needed for a child, utilized a wide range of strategies to surmount the barriers to dental care that they faced. These strategies ranged from reducing cost by going to the dentist for routine check-ups, to gaining welfare as the only means by which their children would receive treatment. All of these families would be classified as having demonstrated effective demand for dental services in the model for utilization of dental treatment.

For some of the families the availability of low-cost, sliding-fee clinics provided the answer when the family was financially eligible. Other mothers went to work to obtain funds for the care they felt their child needed. For many families, finding a dentist who would allow them to pay on time, or who had a bank-plan, or finding a dentist within walking distance who would take them as new patients, were the ways used to obtain the care. Many parents recognized the importance of dental care for their children and obtained it, but sacrificed or compromised on dental care for themselves. Some parents expressed dissatisfaction with the dentist they had previously, and sought care elsewhere. In many instances, parents needed to make several different contacts in order to find a dentist or a community resource where they could obtain care. Persistence seemed to be a strong characteristic of many of these mothers.

While the model on utilization, discussed by Young and Striffler, ${ }^{5}$ is useful while looking at the responses of families to today's delivery-system for dental care, uncritical acceptance of the model can be called dysfunctional in that it does not explain the factors which would be operating in moving families from no demand or potential demand to effective demand.

It appears that many families cannot demonstrate an effective demand for dental services merely by picking up the telephone, calling the dentist's office, making the appointment, getting to the office, receiving the treatment, and paying the bill. Many families, even though they are able to demonstrate effective demand for dental services, have made compromises and sacrifices which would not be readily apparent without intimate knowledge of families' circumstances. Other families have found it impossible to circumvent the barriers to treatment and, therefore, were unable to demonstrate their demand for dental services effectively; they remain hidden within the community. It is through a broader understanding of both the strategies currently used and the extent of the barriers faced that the delivery-system of dental services can become more responsive and enable families to obtain the treatment that they need. 


\section{Summarizing}

This paper reports a study of the problems of parents in gaining dental treatment for their children. In terviewers who were trained residents of the community talked with families of children who were identified as needing dental treatment for carious lesions in one or more permanent teeth, and who, one year later at the second examination for dental screening were found either to have received the dental treatment needed or to have shown no evidence of having been treated by a dentist. Parents were notified of their child's need for treatment following the baseline dental examination conducted at school.

Strategies for obtaining dental treatment were identified from the interviews with families who were successful in obtaining treatment during the 12 -month period of study. Barriers also were identified from the interviews with those families who had been unable to obtain the needed treatment during the year. This paper, hence, reports qualitatively these strategies and barriers through a format of family vignettes. The vignettes have been presented by status of treatment and by socioeconomic status. Seven observations now can be defended by the vignettes reported:

1. the interviews obtained data about families with effective demand, potential demand, and with no demand for dental services, but this model requires additional intimate knowledge of a family's circumstances to explain why it behaves as it does about the utilization of dental services;

2. the strategies used in obtaining dental treatment for a family's children included patronage of a low-cost community clinic when eligible, mothers' assumption of extra jobs outside the home, location of a dentist within walking-distance of the home, finding a dentist who would accept monthly payments or participated in a financing plan by a bank, rationing dental care among members of the family, sacrificing adult care for treatment of children, becoming eligible for welfare, and depending on reminders from the dentist's office to keep routine appointments regularly;

3. persistence and tenacity, described by the large number of contacts which some mothers made, accounted for some of the treatment secured;

4. the barriers to obtaining needed treatment for children included over-crowded community clinics, financial ineligibility (above level of income established) for low-cost clinics, clinics closed during summer months, family's lack of acceptability of dentistry or dentists, lack of family funds, extreme fear shown by children, and overwhelming personal problems;

5. large families of children, divorces or separations, double working shifts, physically or mentally handicapped parents, prison-sentences, hospitalization, and other major health expenses also contributed to interference with dental treatment;

6. impervious barriers, rather than apathy of parents, caused most of the failures to obtain dental treatment; and

7. lack of acceptability of the standard of dentistry practiced (combined with the personality of the dentist or the size of the fees charged) explained why a number of children did not get treatment.

\section{Bibliography}

1. Green, L. W. Manual for scoring socioeconomic status for research on health behavior. Pub. Health Rep., 85:815-27, Sept. 1970.

2. Nikias, Mata K. Social class and use of dental care under prepayment. Medical Care, 6:381-93, Sept.-Oct. 1968.

3. Richards, N. D. Utilization of dental services. p. 209-40. (In Richards, N. D., and Cohen, Lois K., eds. Social sciences and dentistry; a critical bibliography. London, Federation Dentaire Internationale, 1970. 381 p.)

4. Samuels, Joanna J, et al. Family characteristics relating to utilization of dental services for children in need of treatment. Paper read before the 50th Annual Meeting of the International Association for Dental Research, Las Vegas, March 23-26, 1972.

5. Young, W. O., and Striffler, D. F. The dentist, his practice, and his community, 2 nd ed. Philadelphia, Saunders, 1969. XIII + 346 p. (p. 183-207) 